\begin{tabular}{|c|c|}
\hline $\begin{array}{l}\text { Informing Science: } \\
\text { the International Journal of }\end{array}$ & $\begin{array}{l}\text { An Official Publication } \\
\text { of the Informing Science Institute } \\
\text { InformingScience.org }\end{array}$ \\
\hline & Inform.nu \\
\hline
\end{tabular}

Volume 23, 2020

\title{
INFORMED CHANGE: EXPLORING THE USE OF PERSuASIVE COMMUNICATION OF INDIGENOUS Cultures THROUGH FILM NARRATIVES
}

Sonja H Bickford *

Michelle Warren

\author{
Michelle Warren \\ * Corresponding author
}

Department of Communication University of Nebraska Kearney Kearney, NE, USA

Department of Modern Languages University of Nebraska Kearney Kearney, NE, USA bickfordsh@unk.edu

warrenm2@,unk.edu

\section{AbSTRACT}

Aim/Purpose $\quad \begin{aligned} & \text { There is a need to find a way to utilize narrative storytelling in film to make } \\ & \text { students more aware of the impacts of global problems and how they are } \\ & \text { perceived. }\end{aligned}$

Background Two films from the year 2015 from two very different places in the world explore the encroachment and secondary effects of urban civilization upon indigenous cultures.

Methodology
Contribution

Findings

Recommendations for Practitioners
An interpretive, qualitative, methodology was used in addressing and discussing the use of these two films as a persuasive communication teaching aid.

This paper offers an approach to using narratives of films on indigenous issues in education to inform students about real-world issues and the wide impacts of those on various cultures and populations.

Through the discussion of the two films, we suggest that using films with indigenous themes is beneficial to a course curriculum in a variety of subjects from communication to history and politics, to help students visualize the problems at hand. Anecdotally, the authors note that students are more engaged and willing to discuss topics if they have watched films or clips that deal with those topics than if they have simply read about them.

We aim to inform instructors about using compelling narratives in the field of persuasive communication, and adding that both discussion questions about the issues as well as having students reflect on these issues in their own

Accepting Editor Kay Fielden | Received: July 2, 2020 | Revised: August 20, September 7, September 10, 2020 Accepted: September 13, 2020.

Cite as: Bickford, S. H., \& Warren, M. (2020). Informed change: Exploring the use of persuasive communication of indigenous cultures through film narratives. Informing Science: The International Journal of an Emerging Transdiscipline, 23, 107-118. https://doi.org/10.28945/4635

(CC BY-NC 4.0) This article is licensed to you under a Creative Commons Attribution-NonCommercial 4.0 International License. When you copy and redistribute this paper in full or in part, you need to provide proper attribution to it to ensure that others can later locate this work (and to ensure that others do not accuse you of plagiarism). You may (and we encourage you to) adapt, remix, transform, and build upon the material for any non-commercial purposes. This license does not permit you to use this material for commercial purposes. 
lives and careers help in teaching the subjects in a world where visual communication and storytelling is growing.

Recommendations Technology and use of visuals are used as teaching tools in a variety of fields. for Researchers Film narratives can be used as a teaching tool in multiple fields and provide insight about a variety of ideas. Identifying films such as those with indigenous themes provides an example of how one film can bring up multiple, real-world, topics and through led discussion student reflection can potentially lead to self-insights and have lasting impacts.

Impact on Society Creating compelling story lines to show impacts of our daily decisions helps create a broader understanding of their effects for a variety of audiences. We can thus use films such as the two discussed here in learning and teaching about difficult topics, such as climate change, and the oppression of indigenous peoples.

Future Research Additional research and assessment can be done on the impact of teaching with films and their compelling story telling of issues, and what types of questions should be asked to maximize learning and the impact of film narratives.

Keywords indigenous, communication, reflection, education, film, urban development

\section{INTRODUCTION}

Past research has looked at whether the increased usage of technology and visual aids as part of course curriculum has improved learning outcomes. Other research suggests that films may help students ponder on the meanings and implications, and finally change or modify their values, beliefs, and actions. This paper adds to that discussion especially in the area for instructors who teach about ethical decisions, encouraging students to consider behavioral changes. Using films to address and teach about current topics may not only aid in understanding issues, but also show the bigger picture and additional impacts which film narratives address, and how those narratives help open students' perceptions to differing viewpoints and experiences. Thus, informing instructors about the use of stories in films on indigenous issues, where storylines provide insights to various experiences and viewpoints of a relatable, larger, real-world topic, is provided as a solution for instructors.

Employing compelling film narratives improves learning in class, and is helpful for instructors as they strive to communicate a challenging topic to their students, and connect students to it beyond their classrooms. Using films to address and introduce students to different issues helps students in reflective learning. For students in fields such as communication, advertising, and world languages, narrative films may provide insight and help in understanding larger topics and how others view them. Being able to relate to other societies and communities and understand their experiences and viewpoints about a topic will help students relate to others later. Visually seeing the topic at hand may aid in not only understanding the issue, but also the bigger picture, with additional impacts that can be addressed through the narratives of films. Thus, informing instructors about the use of persuasive stories, especially film storylines, is suggested as a tool for instructors. Learning about the world around us through movies has led to new art and media genres emerging in which fictional works show real-world trending topics.

One of the most relevant and popular new genres, coined by Dan Bloom, a journalist, is "cli-fi." Clifi refers to fictional works that involve issues of climate change (Nixon \& Robinson, 2017; Svoboda, 2016). It portrays the human experiences of coping with climate change and is used as a tool to relate the issues of climate change to a target audience (Nixon \& Robinson, 2017). The issues of how people in different parts of the world are affected by and deal with issues such as climate change, or cultural collisions, can be understood more poignantly through films such as Chloe and Theo (Sands, 
2015) and Ixcanul (Bustamante, 2015). Our study of these two films opens the discussion of using film in classes to address interrelated issues and to help students gain an understanding of how topics may be viewed differently by people from different cultures. Not only do the films display a storyline and narrative, but they both also emphasize real-world issues currently being experienced in these remote parts of the world and how people may view issues and the consequences differently. These films, along with others that address difficult problems, highlight real-world issues and events beyond mainstream cinema.

As stated by Wong and Fong (2014), universities and educational institutions are incorporating greater use of information and communications technologies (ICT) into their curriculum to be able to serve their student populations. The drive to use more visual content is present in many institutions and many courses are either supplemented with online material or taught completely online. By increasing the use of information and communication technologies, using compelling storylines such as those found in cli-fi films, can engage students on a new level as the issues are brought to life. By sharing films such as the two described and discussed in this paper students may be able to reflect on and learn about how any given topic may be viewed differently by others. Therefore we state that using film in the classroom to teach a lesson about current events or issues in the real world will aid in increased awareness of how global issues and topics are viewed and experienced in different ways and how through reflection and deeper learning these topics may help students' in their own lives and careers.

A study conducted by Svoboda (2016) regarding how the communication of a message, such as climate change, showed that in films where the central themes have characters obsessing about impending disaster or ending of the world, the audience relates those worries to their own lives. We argue that having a compelling film narrative, with relatable characters and events, will have a positive impact on learning outcomes. To generate a successful appeal to create change, whether behavior or thinking, films can employ images or characters that appeal to the intended target audiences. For example, if the lead character is a scientist, the film resonates with real-life scientists who deal with similar topics as their fictitious counterparts in their daily work (Svaboda, 2016). Narratives, as a tool for social change, are stories - exposure to them can affect viewers' beliefs, attitudes, intentions, and behaviors so that they move into closer alignment with viewpoints espoused in those narratives (Braddock \& Dillard, 2016). As pointed out by Sun and Chen (2016), a question remains on how to transfer the inquiry to the purpose or goal and we add the question of how can an instructor maximize the use of persuasion in films? Keengwe and Kidd (2010) identify that the addition of cognitive tasks where students are asked questions requiring them to think critically, to reason, and to analyze information helped them engage in understanding and retrieving information presented and taught. In this paper, we introduce the use of two films of relevant global topics and then discuss them as examples of the variety of topics presented in the film narratives to highlight the possibility and importance of discussing such films in a variety of courses. However, as Tan (2007) stated, films should be appropriately selected and supplemented by relevant lecture notes, readings, and guidance from the instructors. We add to this by giving an example of ways in which films on difficult topics help create ways to actively engage students with the issues as they are brought to life in the films. We add the question of whether the narratives of the these films herein call for behavioral and/or thought paradigm change in the lives of their audiences and whether they would be beneficial in providing the cognitive tasks required to create an effective dialog as part of the course.

\section{LITERATURE AND THEORY}

Are films a form of persuasive communication calling for action? How can narratives be used in the informing process within the classroom?

The growing trend of moving away from the printed word to the image and now to the moving image impacts the way we communicate, inform, and/or teach (MacDougall, 2003). Persuasive commu- 
nication is defined as any message that is intended to shape, reinforce, or change the responses of another, or others' behavior, belief or feelings towards something or someone, and it plays an important role in creating social influences and changing attitudes (Mohammadi et al., 2013). Using visuals to inform and persuade within the classroom simply meets the demand of the audience. However, a question of how does an instructor best use the narrative or story to inform students about the issues around them?

There are many possible reasons for the recent heightened interest in the narrative in the field of communication studies, one of which is the belief that stories can be an especially potent means of creating opinion change (Braddock \& Dillard, 2016). Stories are used in many cultures as teaching tools as they are relatable to our own lives. According to theorists, a message may be called a narrative if it is a story that contains information about the setting, characters, and their motivations (Braddock \& Dillard, 2016). The aim is to inform and use film narratives as supplemental material in courses and to support the idea of making students more cognizant of issues that may have wider or larger impacts in their own lives and careers. For example, a recent article by de Roo (2019) states that ecological disasters and increasing environmental crises can be narrated through films, impacting audiences' awareness of the environment through their senses. By watching such films the cinematic narrative and experience together has potential to impact an audience member's emotions and give new and broader insight to the issue at hand. Showing films where the story involves people from various and different cultures provides insights and creates awareness of how people of different backgrounds may experience issues in different ways. For example, many may be aware of the Arctic, but do not know what it is like to be living in a remote Arctic village. Through film narratives, we can gain a better understanding of the cultures, the cultural values, and experiences of global issues such as climate change or urban development. Also, Bondi et al. (2020) found that the power of a film's visual appeals in framing climate change showed that there is a long term effect of the film on the audience members' understanding of the issue in question. Also, indigenous-produced and indigenousthemed films are circulating more and more in non-thematic film festivals, receiving prizes and disseminating their own stories to a larger and more diverse audience, which creates possibilities for intercultural interaction and dialogue (Frey \& Brito, 2020).

Based on the definition of persuasion, and the knowledge that film narratives have a powerful and long-lasting impact on an audience member coupled with institutional needs to add narratives to aid in this instruction, we then ask and discuss the best types of films to inform students about the topics being covered. Often the dominant culture is the victor in blockbuster films and the indigenous peoples who appear in them are rarely given a chance to portray their own culture or perspectives. Engaging and informing students about indigenous perspectives help make students more aware of other experiences, points of views, and thoughts about larger (global) issues (Stoddard \& Hicks, 2014). Thus we argue that the two movies, both dealing with indigenous populations and based on real-life stories, have persuasive narratives and are impactful and relevant for classroom use as they show the main characters, their communities, their lives, and the main issues affecting them and both have the presence of larger global issues and showcase the differences in how people experience and view the same issue. Also, the reason for choosing to show these films is that indigenous communities have tended to cultivate learning that is interactive, vibrant, and integrated with traditional knowledge. Thus we state that the use of narratives as found in these films helps create awareness and impact a students' life through long term changes based on the understanding of how values, experiences, and views of issues may vary between people from different cultures. We suggest that instructors create questions that are both analytical and reflective for students to help create a deeper understanding of the global issues and for students to gain ownership over the own the topics and material. By doing this, students will be able to relate the issues discussed to their own lives.

The first movie, Chloe and Theo (Sands, 2015), features Theo Ikumaq playing himself, an Inuit from the Arctic, who travels to New York City to beg U.S. leaders to change the country's environmentally destructive lifestyles so his people can continue living and surviving in the Arctic. The second, Ixcanul 
(Bustamante, 2015), in turn explores how María, a young Kaqchikel woman, dreams of finding her escape from rural indigenous Guatemala plantation work by becoming pregnant with another worker planning to immigrate to the U.S., only to be duped by her plantation manager (and her future husband) into selling her baby and remaining trapped on the plantation for the rest of her life. The ecological and cultural destruction caused by the urban and/or economic development on the lives of indigenous people will be discussed and compared in the two films, as well as how the metropolitan cities portrayed contrast negatively with the tranquil natural beauty of the rural areas depicted. In analyzing the main messages of the two movies, the interactions among the characters are relatable to the audience. The films create a call for a paradigm shift in the viewers because they feel sympathetic toward the issues presented, and are emotionally drawn to think about the characters and story lines, and thus draw parallels to their own lives.

\section{METHOD}

In this research, we used an interpretive, qualitative methodology guided by insights into indigenous cultures and persuasive communication in two films produced in 2015 to examine the portrayal of geographically different indigenous communities and cultures that are both impacted by urban and economic development and greed. The films were chosen based on the idea presented by Stoddard \& Hicks (2014) that represent voices and stories of indigenous communities, but also as case studies as discussed by Stanton et al. (2019). We chose the two films produced in the same year that represent geographical and cultural differences and discuss those based on the reflection of the key global issues that cross these cultures. This, followed by the discussed of the films' main issues, serves as case examples of the deeper instructor-led discussion that will generate long-term impacts and learning together with the students' reflection of those issues in their own lives.

\section{ANALYSIS OF INDIGENOUS CULTURES IN FILMS}

\section{INTRODUCTION OF FILMS}

Using the two films about two different indigenous communities and two radically different parts of the earth that portray multiple real-world issues that impact people all around the globe. The first film, Chloe and Theo, is an American independent drama written and directed by Ezna Sands in 2015. The second film, Ixcanul, was also produced in 2015 and is a Guatemalan-French co-production written by Jayro Bustamante. Both films' narratives and persuasive messages are based on the characters' real-life experiences and serve as examples of how film narratives can inform students about the different impacts of global issues. We believe, as suggested by Keengwe and Kidd (2010), that the addition of cognitive tasks where students are asked questions where they were required to critically think, reason, and analyze information such as through a deeper instructor-led discussion and reflective questions about these issues, the films could benefit learning and have long term impacts on students' lives as they become more aware of differing experiences and views of issues impacting us globally.

\section{CHLOE AND THEO}

In the film Chloe and Theo (Sands, 2015), Theo is sent from his Arctic village to New York City to speak to the leaders of the Western World about how to keep his northern world from melting. The film highlights Inuit and indigenous life from his village, his people, showing cultural differences between indigenous culture and thinking with life in the western world. These cultural beliefs and behavior differences are stressed throughout the movie as Theo Ikumaq (played by himself) interacts with Chloe (played by Dakota Johnson) and his other new New York friends. The visualization generates discussion of cross-cultural issues as part of the narrative and how people from different cultures complete daily tasks. 
In the opening scene, we see the hot sun and an Inuit running away on a melting ice sheet. This depicts the main issue of the film; the world is melting for the Inuit village living in the Arctic. Theo is chosen by his elders to travel and spread his message, seeking a solution for the problem.

Showing the Arctic way of life with the sled dogs and scenery creates the image in the audience's mind of what life in an Arctic village is like. That image is then countered with that of the sun melting the ice, relaying the urgent message of the Arctic thawing. As Theo packs and travels to New York City, we immediately see the contrast for the Inuit native as he experiences culture shock of the unknown and new world. This is seen especially through Theo's attire and behavior while walking through the city, as he would in his home village. Also, the miscommunication between the cultures is shown through cultural differences. Theo asks to speak to the elders. In indigenous cultures, elders are the esteemed leaders of the community. Theo is surprised to be taken to a sad, run-down old folks' home. The elders in a busy city like New York are seen as the useless, elderly retired people, shuffled away into rest homes. Chloe, a homeless woman living in the streets of New York, befriends Theo and introduces him to her friends. With her help, he tries to meet with the leaders at the United Nations, and by happenstance, he meets a UN employee who overhears his story and decides to take action.

A key insight from the movie occurs when Theo realizes that it is the media - not the leaders - that holds the power to communicate and create change in people. He states:

... we are too late - your leaders don't have the power to change anything, your television sets have the real
power, they compel you to buy things that you do not need ...., they tell you to drive cars that cannot even
move because everyone else is driving one and cities with no clean air. They mock the way you look and affect
your happiness. What can your leaders do about your nature when it is so corrupted that when you live each
day based on consuming, devouring, and wasting ... never happy ... My message should be for my own peo-
ple that we must prepare for the sun's case (meaning that the sun is melting the Arctic and his village) for it
is surely coming sooner than we think. (Sands, 2015)

This is a very powerful message, not only in the movie but for the audience as they too are shown the deteriorated state of the current environment and life as we know it. The film iterates that we, as citizens, hold the power of televisions and social media messages over our elected leaders' words and acts. This message drives home the point that action must be on an individual level and in our communities, not directed by large national or international directives, as these do not change behavior.

In the closing scene, the commentary is provided by Chloe. She explains what Theo has taught her, and how he has managed to change her views on life. She demonstrates how her thinking and behavior have changed through their friendship and what happened to Theo as he was murdered on the streets of New York City for his brand new, expensive running shoes he had received moments before his walk. In the emotional final scene, reality hits. The audience shares a view of Theo's final thoughts as he lay dying: the film flashes back on peaceful memories of his Arctic village. Chloe, in a voice-over, states that Theo wanted the world to be beautiful and that he simply wanted to selflessly change the world and share what his world is like. In Theo's voice, he states that "- there is a lot of snow - you realize that you are standing on sacred ground, underneath you are cathedrals of ice - what stories are they telling - this is my home." Chloe adds to this in her closing commentary. She hopes that he has gone home to his life - she asks for a revolution - "a revolution of mind". The audience sees and hears from Chloe how she has changed - she has learned that there are people who love her and that she indeed has a great life. In her last commentary, she states "Don't think - feel" (Sands, 2015). This comment and her realization show the target audience for the movie the process of how Chloe has been impacted and changed, and how the audience can relate to her and change their overall thinking, leading to new behaviors in how they purchase things or how their actions can impact others near and far. Her appeal contrasts with the feelings that she has experienced with her time with Theo when she lived on the streets. After meeting Theo, she has developed the ability to empathize with others. Her call for an 
emotional reaction asks the audience to reflect with empathy toward Theo and the plight of his people as their home melts, thus urging spectators to change the way they currently treat the environment. The film, during this reflective and poignant moment, adapts a cinematic trick to draw attention to the message: the real-life shot switches here briefly into animation, making the spectators stop and contemplate the issue of climate change.

\section{IXCANUL}

Ixcanul takes place in rural Guatemala on a coffee plantation. It opens and closes in nearly identical scenes - young protagonist María (played by newcomer María Mercedes Coroy) being dressed in traditional celebratory clothing by her mother; in the beginning, to meet her soon-to-be husband, plantation foreman Igancio; in the end, to marry him. The repetition of this scene in the opening and closing of the film (with a few key differences discussed below) suggests a circularity symbolic of the cycle that keeps indigenous Guatemalans in a state of defenseless poverty, victims of Spanish-speakers who keep them ignorant to suit their own needs. In this film, we found that Bustamante (2015), in his first full-feature, plays with the binary oppositions of the city versus countryside (favoring the latter), and then overturns that binary when he shows how one has infiltrated into the other, contaminating life in the country (Warren \& Bickford, 2020).

The characters who drive the film from its slow and studious opening scene are seventeen-year-old María and her steady-handed mother. They lead a seemingly bucolic life, tending to their pigs and chickens, engaging in almost ritualistic bathing together, and delivering offerings to the omnipresent, always smoking volcano that dominates the background. Though María is betrothed to Ignacio, one of the plantation foremen, she seeks to escape via a carefully planned sexual encounter (leading to pregnancy) with the younger and misguided Pepe, who plans to leave for the USA (“... behind the volcano, it's the United States..." [Bustamante, 2015]), in search of a better life.

As discussed by Warren and Bickford (2020), it appears that the natural world Maria lives in serves almost as a mentor/teacher for her coming-of-age. She learns of the connection between sexual desire and alcohol as she helps her mother get the pigs drunk on aguardiente so they will procreate. She experiments with her sensual desires, and how to fulfill them, as she practices kissing a tree, strad-

dling it and riding it as if it were her lover. These scenes present the natural world as a lush green natural innocence, unaltered by modern civilization, providing María with a safe way of experimenting with her sexuality. Eventually, María puts her lessons into action, waiting for a very drunk Pepe outside the local tavern and seducing him.

After María becomes pregnant, we see that all that is countryside is not necessarily pastoral, almost as if her passage into womanhood and losing her virginity invites difficulty into the village. First, we see María and her mother pouring jugs of toxic anti-dengue chemicals into the plantation's water supply. Next, the plantation suffers from a venomous snake infestation. The snake-killing chemical Ignacio brings from the city (originally from the US - so "it must be good") makes María and her father feel ill from the fumes. Due to traditional beliefs, none of the indigenous workers want to be responsible for the killing of the snakes, nor will they work the fields while snakes are present. It should be noted that serpents, plumed serpents, and calm snakes are examples of the sacred nature of snakes in Mayan beliefs as noted in Tedlock's $(1985,2013)$ translation of the Popol Vuh.

María's mother, something of a traditional healer, believes that since she is pregnant, María has the power to scare the snakes away and make the plantation safe again. In her attempts, María is bitten the ensuing rescue scene delves deeper into the dark chaos of the urban center and its effects on the small indigenous community living in the country.

As Ignancio rushes María to the city for medical help, María's mother rides with her in the back of the pickup, holding her in her arms, begging for her survival, and apologizing for letting her try to eradicate the snakes. At an hour and several minutes into the otherwise quiet and unrushed narrative, the cinematography reflects a sudden stylistic change as the characters speed toward the city. Film 
critic D’Angelo (2016) notes “... Bustamante accompanies this abrupt shift from the country to the city with an equally abrupt formal shift, going jagged and handheld after nearly an hour of expertly composed shots in dreamy soft focus." Indeed, the tone swings from one extreme to the other. The long, silent languid shots ranging from the opening scene, where María stares unabashedly into the camera as her mother dresses her, to the almost oneiric views of the plantation landscape with the omnipresent volcano smoking in the background, take on a complete alteration as the crisis moment arises and the family speeds toward the city. The slow, leisurely views disappear, and the camera jolts shakily along with Ignacio's pickup as they approach the hospital. The streets are noisy, crowded, and confusing. Traffic screeches around the characters, and Castilian Spanish, which only Ignacio speaks, clutters the air. The clamor in the boulevards and inside the hospital reflects what it must feel like for the three non-Spanish speaking characters to be surrounded in a cacophony and chaos of unfamiliar sound, fearing for María's (and the unborn baby's) life as the poison courses through her body.

The hospital scene is pivotal in positioning and reinforcing several binary oppositions: country/city, languid/rushed, Kaqkichel/Spanish, indigenous/non-indigenous, impotency/power. Life in the countryside, while not always easy, is depicted cinematographically as tranquilly slow, filled with the resonating clicks of Kaqchickel and visually stunning lush vegetation in the foreground of the slow rolling smoke from the volcano. The city and hospital, by contrast, are shown in choppy, jiggling frames, filled with noise and confusion as the indigenous family struggles to make sense of what is happening to María. The final piece that places the urban center as the malevolent force that it is in Ixcanul is Ignacio, the character who lives on the cusp between city and country (Spanish and Kaqchical), and his betrayal of María and her parents.

Ignacio, indigenous himself but savvy in the ways of city life and fluent in Spanish, lies to the family, telling them that while María will recover from the snake bite, the baby did not. He encourages María to unwittingly sign adoption papers, convincing her that she is agreeing to receive money from the government for the supposedly dead baby's funeral. This betrayal is key in appealing to the audience members' sympathy toward María and her unsuspecting parents - the implied viewer is privy to Ignacio's machinations and sees how he (and other officials later) trick María and posit her as a victim of those (here, Ignacio) who have the power of Spanish language to assert control over the powerless indigenous.

Upon returning to the plantation, María mourns the death of the baby, putting the tiny coffin to rest in the ground. However, she never fully accepts the baby's death and eventually digs up the grave to find only a brick inside. Realizing the baby did not die, the family returns to the city with Ignacio, once again as their unreliable translator, asking officials to help them locate it. The injustice of the situation is revealed only to the audience members who can follow Spanish (or English subtitles); the officers threaten to turn María in for selling her baby illegally. Of course, the only one who understands the situation but who does not adequately explain it to María and her family is Ignacio. This second city scene reinforces the opposition of the oppressive, urban versus the more peaceful countryside. In the city, the indigenous characters are again fooled and betrayed because of their ignorance of the language tied to those who colonized Guatemala and people from the city, rendered powerless because of their inability to function outside of their Kaqchikal. As María's mother frantically pleads with the officers to help them find the baby (in Kaqchikal), the officers calmly remind Ignacio (in Spanish) that, should they investigate the issue further, María could be arrested for the crime of selling the infant. The officers can see that neither María nor her family could have understood the papers written in Spanish that María "signed" to give up the baby. However, rather than addressing the root of the problem (Ignacio, for fooling his indigenous "friends"), they put unsuspecting María in the guilty position of having sold her baby for profit. Maria's father accepts a bag of coins from Ignacio in exchange for forgetting the events surrounding the pregnancy. The money presumably goes toward purchasing the heavy silver earrings and necklace with which María's mother dresses for her wedding in a closing scene otherwise almost identical to the opening. The other principal difference 
in the final shot is that a crumpled, lacy veil enshrouds María's head in the film's final frame, eerily erasing her face and rendering her invisible, underlying her impotence in determining her own future.

\section{INFORMING AND LEARNING THROUGH THE MAIN ISSUES}

The main theme in Chloe and Theo is climate change and how it is viewed in the western world; in this case, New York City versus the Inuit Village in the Arctic. In addition, the film brings to light the impact of our actions and decisions and what impact they may have on others. The main issue and the movie's main message revolves around the phrase "our world is melting - please help us" (Sands, 2015) that is stated throughout the movie as Theo is sent to deliver his plea for help to the leaders of the Western World. Theo makes a meaningful conclusion/resolution based on his time and experience in New York City and through the interactions with the people there that their melting world cannot be saved, and the only resolution is for his village and those in the Arctic to adapt to this impending melting of the Arctic. Svaboda (2016), in an analysis of cli-fi movies, shows that successful examples of fictional works' efforts to mitigate the causes of climate change are almost entirely missing from most films, and only a few address ways to adapt to its consequences. As such, in Chloe and Theo, the realized conclusion of the mission is to seek change in behaviors and actions from the Western leaders and people, but no solutions beyond the insight of the conclusion is offered. In Ixcanul, the infringement of dominant western culture is seen infringing both discreetly and overtly into the indigenous peoples' lives (poison to kill snakes, language to continue the oppression of nonSpanish speakers, dreams of a prosperous life in the USA just beyond the volcano, and the ubiquitous international market for Guatemalan coffee) creating a greater disparity between the powerful and the vulnerable. Ixcanul does not offer a finite solution to its problems either but instead appeals to spectators through the sympathetic characters of María and her parents. They, and others like them, will not stand a chance for justice without a redistribution of power.

\section{MAKING TOPICS REAL: THE IMPORTANCE OF NARRATIVES}

As students are more and more frequently exposed to different media and technology resources, from audio to printed material, they lack the motivation for learning conventionally (Ismaili, 2013). A study of 243 trainee teachers enrolled in a module in an institute of education where films are used to promote reflective learning showed that using films is useful for their reflective learning, but when using films they need to be paired with appropriate lectures, readings, and guidance from the instructors (Tan, 2007).

Based on our own teaching experience, we find that students increasingly relate to new concepts and new views through varied types of media, such as film. As stated by Sun and Chen (2016) about the transferability of the instructional method (in this case, the use of narratives in films) to the instructional aims and Keengwe and Kidd's (2010) point regarding the generation of effective cognitive tasks help students engage, enabling them to understand and relate to the lessons taught. We suggest that persuasive film narratives, especially with the relatable impending doom scenarios as suggested by Svaboda (2016) where the students relate those worries and reflect upon those in their own lives can be taught by adding a mix of discussion questions that are both analytical to the topic in question and reflective to the students' own life. Cli-fi film or film with indigenous narratives are beneficial as an instructional tool in providing the cognitive thinking tasks required to supplement the learning goals as part of a course. This could be highly beneficial in courses where global issues are discussed such as in communications, marketing, politics, history, social studies, and other disciplines. The use of narratives, and especially visual narratives such as films, is supported by the growth in the use of social media applications and videos and/or visuals used in recent instruction. With more than 100 hours of videos posted online every minute in sites like YouTube, we see that multimedia content is becoming a significant source of communication and exchange of ideas (Mohammadi et al., 2013). 
Thus, the visual narrative showing compelling and relatable issues and topics together with added insight about indigenous cultures and experiences can help students understand the complex issues and impacts of decisions.

From our experience in the classrooms (both online and face-to-face), we reflect and have found that to create a learning environment and address impacts for student and audience behavior, films like Chloe \& Theo and Ixcanul play an important role. For example, in courses where we discuss rural development, indigenous communities or cultures, or larger issues such as climate change and how they impact what we are learning in the classroom (whether it is ethical business decisions or writing advertising copy), we have come to understand that showing with relatable storylines about crises and people's worries can help in the understanding of the situation. Thus showing a film such as this as part of a course in history, social studies, but also in the author's experience in communication, advertising, and language classes helps bring awareness to not only global issues, but also how people differ in their views and experiences of that very issue. Indigenous cultures and traditional knowledge are often not discussed and could add insights into improving communication and awareness in students' lives and careers as they strive to communicate with people from different parts of the world. By understanding and reflecting on the situation and issues, through guided learning and reflection, we can then discuss the lessons learned and how these relatable narratives set the stage and emphasize issues that need to be taken into consideration. By watching indigenous films they also provide learning experiences about urbanization and climate change issues relating to indigenous cultures. The discussion and instructor-led reflective learning help students relate to others and understand how others may see or experience the same issue differently and, as stated by Bondi et al. (2020), there may be long-term effects of the film on audience members' understanding of the issue in question. Also, adding indigenous-centered films creates increased possibilities for intercultural interaction and dialogue (Frey \& Brito, 2020). We note that while these films do not necessarily propose overt solutions, they do draw attention to and sympathy for the problems, creating awareness in audiences that they in turn can use in their own lives.

\section{CONCLUSION}

Research has shown that narratives that are communicated toward an audience with relatable issues and recommended solutions are important when creating a persuasive message for change (Braddock \& Dillard, 2016). The change can be for behavior or lifestyle, or even simply a change for the way we think. Becoming informed about an issue will help in creating better solutions.

In any discipline, students learning about their subject must understand their audience and what issues and worries they may have. Film narratives aid in creating a visual or relatable example of issues impacting different communities and about how people's traditions, values, and experiences may differ about the same topics, such as climate change or urbanization, around the world. As Svaboda (2016) states, films that show real-world issues, like the two discussed here, can provide entertainment; however, they can also teach about topics that may be of interest to us and expand our thinking on issues that we may not otherwise be aware of. Big social issues together with films on indigenous topics where we not only learn about the issues but also come to understand the different experiences, give reason to show challenging films as part of courses to bring awareness to these differences. This in turn can help students in their lives as they may gain long-term insights to help them improve intercultural communication and gain an understanding of the different perspectives of important global issues.

We believe that the two films discussed here, Chloe \& Theo and Ixcanul, use information about lifestyles and issues that are realistic to their cultures and communities, making the issues relatable with Western thinking and living. Also, they inform not only teachers but also students about important global issues. Adding questions about relatability will help in the learning of these topics. The cinematography and indigenous languages used augments the goal of raising awareness of the issues the 
characters face. Being informed about these issues and instructed on how to better relate to others is crucial, but more important is the internalizing and understanding these lessons provide.

The films discussed have persuasive narratives from an indigenous perspective that help to bring together humanity, asking what is best for our world, and how our actions impact it, and how do we move forward to solve these problems together.

\section{REFERENCES}

Bondi, B. A., Monani, S. B., Principato, S., \& Bartlett, C. (2020). Examining the impact of climate change film as an educational tool. Applied Environmental Education \& Communication, 1-17. https://doi.org/10.1080/1533015X.2020.1780997

Braddock, K., \& Dillard, J. P. (2016). Meta-analytic evidence for the persuasive effect of narratives on beliefs, attitudes, intentions, and behaviors. Communication Monographs, 83(4), 446-467. https://doi.org/10.1080/03637751.2015.1128555

Bustamante, J. (Director). (2015). Ixcanul [Motion picture]. La Casa de Production.

D'Angelo, M. (2016, August 16). Ixcanul is a debut more explosive than the volcano it's named for. AV Club. https:// film.avclub.com/ixcanul-is-a-debut-more-explosive-than-the-volcano-it-s-1798188595

de Roo, L. (2019). Elemental imagination and film experience: Climate change and the cinematic ethics of immersive filmworlds. Projections, 13(2), 58-79. https://doi.org/10.3167/proj.2019.130204

Frey, A., \& Brito, T. (2020). Indigenous cinema in expansion: Challenges and promises of an intercultural relationship. Canadian Journal of Film Studies, 29(1), 163-182. https://doi.org/10.3138/cjfs.29.1.09

Ismaili, M. (2013). The effectiveness of using movies in the EFL classroom - A study conducted at South East European University. Academic Journal of Interdisciplinary Studies, 2(4), 121. https://doi.org/10.5901/ajis.2012.v2n4p121

Keengwe, J., \& Kidd, T. T. (2010). Towards best practices in online learning and teaching in higher education. MERLOT Journal of Online Learning and Teaching, 6(2), 533-541.

Mohammadi, G., Park, S., Sagae, K., Vinciarelli, A., \& Morency, L. P. (2013, December). Who is persuasive?: The role of perceived personality and communication modality in social multimedia. Proceedings of the 15th ACM on International conference on Multimodal Interaction, 19-26. https://doi.org/10.1145/2522848.2522857

MacDougall, R. (2003). Information, interactivity, and the prospects of a global citizenry: An inquiry into the nature and function of online news. Proceedings of the 2003 Informing Science and Information Technology Education Conference, Pori, Finland, 1057-1076. https://doi.org/10.28945/2689

Nixon, R., \& Robinson, K. S. (2017). Literature and the Cli-Fi imagination. Teaching Climate Change to Adolescents: Reading, Writing, and Making a Difference, 51. https://doi.org/10.4324/9781315276304-4

Sands, E. (Director) (2015). Chloe and Theo [Motion Picture]. Arctica Films

Stanton, C. R., Hall, B., \& Carjuzaa, J. (2019). The Digital Storywork Partnership: Community-centered social studies to revitalize Indigenous histories and cultural knowledges. The Journal of Social Studies Research, 43(2), 97-108. https://doi.org/10.1016/i.jssr.2018.08.001

Stoddard, J., M, A., \& Hicks, D. (2014). The burden of historical representation: The case of/for indigenous film. The History Teacher, 48(1), 9-36.

Sun, A., \& Chen, X. (2016). Online education and its effective practice: A research review. Journal of Information Technology Education: Research, 15, 157-190. https://doi.org/10.28945/3502

Svoboda, M. (2016). Cli-Fi on the Screen(S): Patterns in the representations of climate change in fictional films. Wiley Interdisciplinary Reviews: Climate Change, 7(1), 43-64. https://doi.org/10.1002/wcc.381

Tan, C. H. P. (2007). Reel life teaching: Nurturing reflective learners through film in initial teacher education. Education Today, 57(1), 11-17.

Tedlock, D. (1985). Popol V ub [Trans.] Simon \& Schuster, Inc. 
Tedlock, D. (2013). Popol V uh: The Mayan book of the dawn of life. eBookIt.com.

Warren, M., \& Bickford, S. H. (2020). Market demands and the perpetuation of poverty: City versus country in Jayro Bustamante's Ixcanul. El ojo que piensa. Revista de cine iberoamericano, 20, 11-20. https://doi.org/10.32870/elojoquepiensa.v0i20.319

Wong, L., \& Fong, M. (2014). Student attitudes to traditional and online methods of delivery. Journal of Information Technology Education: Research, 13, 1-13. https://doi.org/10.28945/1943

\section{BIOGRAPHIES}

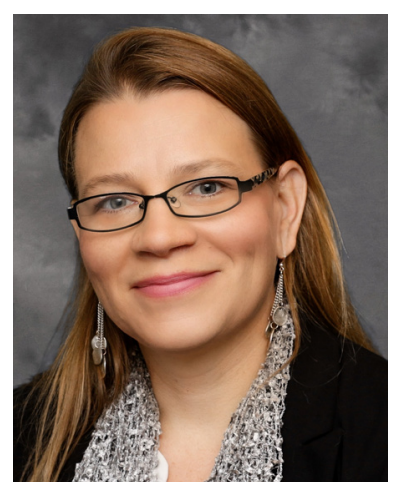

Dr Sonja Bickford is an Assistant Professor of advertising in the Department of Communication at the University of Nebraska Kearney, USA. She has a BS in Management, MBA and is a doctor of business administration in global business and leadership. Prior to her current appointment at University of Nebraska Kearney Dr. Bickford was an Assistant Professor of Business at the University of Great Falls in Montana, as well as the director of study abroad and continuing education. She was also a key member of an international research project on best practices of environmental impact assessments in the Arctic. She founded the research laboratory at the University of Nebraska Kearney entitled the Arctic and Rural Research Center (A.R.R.C.) and her current research project include best practices of communication, corporate social responsibility in the Arctic and rural areas, Aquaponics best practices, and martial arts leadership and communication. Her overall research interests include Arctic business practices, environmental impact assessments, international business cultures, social impact assessments, corporate responsibility, and best practices.

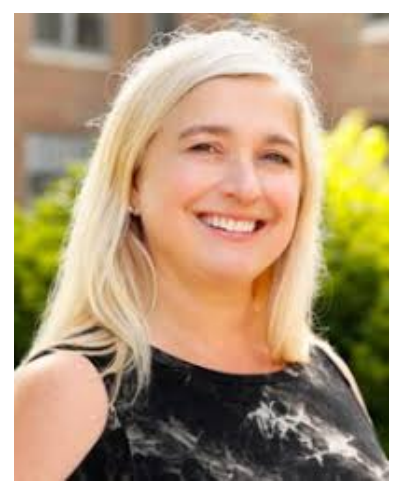

Dr Michelle Warren is an Associate Professor of Spanish. She graduated with a degree in Spanish and French from UNK. She completed her graduate studies in Spanish and Latin American theatre and performance from the University of Kansas. She has studied and taught in Argentina, Omaha, Los Angeles, and Spain. Professor Warren enjoys teaching all levels of Spanish language, theatre, film, and narrative from Spain, Latin America, and the US. Outside of the classroom, Professor Warren leads a summer immersion program at the Universidad de la Coruña on Spain's beautiful northwest coast. She also organizes UNK@TheWorld, an international film series that takes place in downtown Kearney's historic World Theatre. Professor Warren's research interests include themes of culture, nationality, and ethnicity; and how theatre, performance, and comedy contribute to both the affirmation and the questioning of them. 